\title{
Detection and Treatment of Depressive Syndromes in a Rural Island Clinic
}

\author{
Matthew A. Thompson, Jürgen Unützer, MD, MPH, Wayne J. Katon, MD, \\ Jobn P. Geyman, MD, David Gimlett, $M D$, and Edward A. Walker, MD
}

Background: Major depression is a serious and often persistent problem for $\mathbf{5}$ to $\mathbf{1 0}$ percent of patients in primary care. The detection and treatment of depression can be a particular challenge in rural settings. This study describes patterns of care for depression at a rural primary care clinic on an island off the coast of Washington State.

Methods: For a period of 2 months, 226 primary care patients were evaluated for depression using a twostage screening method. Structured chart abstraction was conducted for patients meeting criteria for major depression or dysthymia.

Results: Ten percent of the study sample met Diagnostic and Statistical Manual of Medical Disorders, fourth edition, criteria for major depression, 4 percent met criteria for dysthymia, and 8 percent met criteria for major depression and dysthymia. of the patients who had a diagnosis of major depression or dysthymia by the PRIME-MD, approximately 50 percent had their condition detected by their primary care provider, and approximately 50 percent received guideline level antidepressant treatment. Less than 40 percent of patients whose depression was treated with antidepressants made more than two visits during the 8 weeks after the initial prescription.

Conclusions: These findings are consistent with those from other primary care settings and suggest that there are many opportunities for improving the quality of care for depressed patients in rural primary care settings. (J Am Board Fam Pract 1999;12:120-7.)

Major depression is a serious and often persistent problem for 5 to 10 percent of patients who seek care from primary care providers. ${ }^{1}$ Dysthymia, a more chronic form of depression, occurs in an additional 5 percent. Depression can cause intense feelings of sadness, guilt, self-doubt, and hopelessness. Patients with major depression or dysthymia have been found to be more impaired in social and vocational functioning than patients with major chronic medical conditions, such as hypertension, diabetes, and arthritis. ${ }^{2}$ Researchers have also found that depression causes amplification of somatic symptoms and additive functional impairment in patients who have comorbid affective dis-

Submitted, revised, 15 June 1998.

From the School of Medicine (MAT), the Department of Psychiatry and Behavioral Sciences (JU, WJK, EAW), and the Department of Family Medicine (JPG), University of Washington, Seattle; and the Inter-Island Medical Center (JPG, DG), Friday Harbor, Wash. Address reprint requests to Edward A. Walker, MD, Department of Psychiatry, University of Washington, Box 356560, Seattle, WA 98195.

This study was supported by a summer research grant from the Stanley Foundation (Matthew Thompson). orders and chronic medical illness. ${ }^{3,4}$ Recent studies also suggest that depression can cause physiologic worsening of such medical illnesses as diabetes and coronary artery disease. ${ }^{4}$ It has also been shown that days of work missed because of depression result in an annual loss of billions of dollars in the United States. ${ }^{5}$

Although common in outpatient primary care settings, major depression is often not recognized or treated adequately. Perez-Stable and colleagues ${ }^{6}$ suggested that major depression goes undetected more than 50 percent of the time in primary care settings. Although there might be no major differences in prevalence of depression between rural and urban settings, ${ }^{7,8}$ outcomes for major depression can be worse in a rural primary care practice. ${ }^{9}$ Despite the availability of numerous successful pharmacologic and psychotherapeutic interventions, treating depression in rural settings can be a particular challenge because of limited access to mental health support and services. ${ }^{10,11} \mathrm{~A}$ study conducted by Rost and colleagues ${ }^{12}$ suggests that two thirds of rural primary 
care patients given medication for depression are not receiving treatment concordant with Agency for Health Care Policy and Research guidelines; only 7 percent of these rural depressed patients saw a mental health specialist during a 1-year period. Other common barriers to detection and treatment of depression in primary care can arise from somatization, fears of offending the patient, concerns regarding reimbursement, stigma related to depression, ${ }^{13-16}$ and the increased physician time needed to review psychosocial stressors and symptoms and to provide patient education.

In this report we examine the patterns of care for patients with major depression or dysthymia at the Inter-Island Medical Center (IIMC), a rural island primary care clinic on San Juan Island, Wash. Our study had the following specific objectives:

1. Assess recognition and treatment patterns for patients with major depression or dysthymia at the IIMC.

2. Define usual care for depression as baseline data for a planned study of quality improvement for depression.

3. Interview island health care providers to better understand the medical and mental health services available to this rural island community and barriers to care for depression on the island.

\section{Background}

The San Juan Islands are located in northwest Washington State. Of the roughly 100 islands in the group, San Juan Island, at 55 square miles, is the largest. According to 1990 census data, San Juan Island is the most populated of the islands, with more than 5000 permanent residents. The median age of residents is $\mathbf{4 2 . 2}$ years; approximately 20 percent of the residents are aged 65 years or older, and approximately 20 percent are younger than 18 years. The median household income on San Juan Island is $\$ 34,592$; however, the distribution is bimodal, with the top 15 percent earning more than $\$ 75,000$ and the bottom 15 percent earning less than $\$ 15,000$. Nearly one third of the island residents live within the city limits of Friday Harbor; the town serves as the county seat as well as the major center for commerce and tourism. During summer months the island population can more than double as a result of tourists and seasonal inhabitants. The island is accessible only by boat or air. A ferry from the mainland city of Anacortes, approximately 90 minutes away, provides service to the island several times a day. A small airport accommodates general aviation and commercial connecting flights.

Most medical services on the island are currently provided by the IIMC, and an emergency medical system comprised of 2 paramedics and 26 volunteer emergency medical technicians. The IIMC serves San Juan Island and small neighboring islands with a staff of 4 family physicians and 1 nurse practitioner. The clinic physicians share a regular call schedule 24 hours per day, 7 days a week. Although not an acute inpatient facility, the IIMC is fully equipped as an emergency care facility and can provide necessary laboratory, radiographic, and support services. An 85-bed convalescent center adjacent to the IIMC is also served by the medical center. The medical center has also made space available to regularly visiting specialists. ${ }^{17}$

The North Islands Counseling and Psychotherapy center provides outpatient mental health services for San Juan Island. The clinic staff is comprised of 1 off-island psychiatrist who visits the clinic twice monthly, 1 part-time and 1 full-time doctoral-level psychologists, 3 parttime master's level therapists, and 2 full-time bachelor-level counselors. In private practice the community is served by approximately 7 master's level therapists and 1 part-time doctoral-level psychologist.

\section{Methods}

\section{Two-Stage Patient Screening Process}

For a 2-month period a three-item screening questionnaire was administered to a convenience sample of 226 patients at the IIMC. Patients were given the screening questionnaire by a nurse or a research assistant after verbal consent and before their visit with a primary care provider. The questionnaire was used to elicit symptoms suggestive of major depression or dysthymia. Two items were from the PRIME-MD, an instrument found to be useful for the detection of common mental disorders in primary care settings. ${ }^{18}$ An additional item on insomnia was added by the research team, but it did not improve the sensitivity of the screening instrument. Excluded were patients younger than 18 years, patients who did not speak English, and patients who could not be reached by telephone.

Patients who had at least one positive response 
on the initial questionnaire were sent an approach letter and informed consent form for further screening. Approximately 1 week after mailing the letters, patients were contacted by telephone. After verbally consenting to participate in the study, the patients were given a structured interview consisting of 15 questions concerning current and past symptoms and treatment for depression. The first 10 questions were from the major depression section of the PRIME-MD, an interview based on DSM IV (Diagnostic and Statistical Manual of Mental Disorders, 4th edition) criteria, which have been shown to have 57 percent sensitivity, 98 percent specificity, and a positive predictive value of 80 percent for the diagnosis of major depression. ${ }^{18}$ Patients were also asked two questions to clarify whether they had discussed symptoms of depression with their primary care provider, and if so, what if any diagnoses and recommendations were made. The final three questions inquired about past or current treatments for depression or anxiety-including pharmacologic interventions, psychotherapy, or alternative forms of therapy.

\section{Chart Review}

A structured chart abstraction was conducted for patients who met criteria for major depression or dysthymia according to the PRIME-MD interview. A board-certified psychiatrist $(\mathrm{JU})$ reviewed the charts to look for probable medical causes of depression, such as hypothyroidism or medications, which would exclude the patients from the study, and to assess the adequacy of detection and treatment of major depression. To ensure consistency, detection and pharmacologic treatment of major depression were compared with guideline level treatment as recommended by the Agency for Health Care Policy and Research (AHCPR) depression guidelines in primary care. ${ }^{19}$ Specifically, we looked for adequate dose (using the lowest dose recommended by the AHCPR guidelines) and duration (90 days or more) of antidepressants. The guidelines also recommend follow-up visits every 2 weeks during the acute phase and a visit at 8 to 10 weeks to evaluate treatment response. We used somewhat more lenient criteria for follow-up visits in the acute phase, requiring three or more visits in the first 2 months of treatment and an evaluation of treatment response at 8 to 10 weeks.
Interview of Community Health Care Providers

In addition to the 5 primary care providers at the clinic, several mental health providers and a massage therapist were interviewed. All those interviewed were asked to describe their perception of depression as a health problem on the island, their role in treating patients with affective illness, and barriers to diagnosis and treatment of depression.

\section{Results}

\section{Study Sample}

Results of the two-stage screening process are outlined in Figure 1. The first-stage screening questionnaire was offered to 226 patients. Of these patients 32 (14 percent) refused to participate, 112 (58 percent) had negative responses, and 82 (42 percent) had positive responses. Of the 82 patients who responded positively, 3 did not have telephones, 3 could not be reached for follow-up, and 5 refused to participate in the telephone follow-up interview. Seventy-one patients, 87 percent of those who had positive responses, were contacted by telephone; of these 11 (16 percent) refused to participate in the telephone interview. Of the 226 patients who took the initial screening test, 172 were included in the final study sample. Nonparticipants' average age was 54.3 years ( $n=54$, SD 17.0 years), and 72 percent were female (95 percent confidence interval [CI], 59 to 85 percent). Participants' average age was 55.0 years $(n=172$, SD 18.4 years), and 64 percent were female (95 percent CI, 57 to 73 percent).

Of the 60 patients who agreed to the telephone interview, 37 had a negative screening interview for major depression or dysthymia, and $17 \mathrm{met}$ criteria for major depression with the PRIMEMD. Of these patients, 4 met criteria for major depression alone, and 14 met criteria for both major depression and dysthymia (double depression). Six met criteria for dysthymia alone.

Prevalence estimates of these disorders were calculated for the study sample of 172 and are summarized in Table 1 . The total prevalence of major depression determined with the PRIME$M D$ was 10 percent $(n=17,95$ percent $C I, 5$ to 15 percent). Eight percent ( 95 percent $\mathrm{CI}, 4$ to 12 percent), or 14 of the 17 cases of major depression, met criteria for both major depression and dysthymia (double depression). The prevalence of dysthymia alone was 4 percent $(n=6,95$ per- 


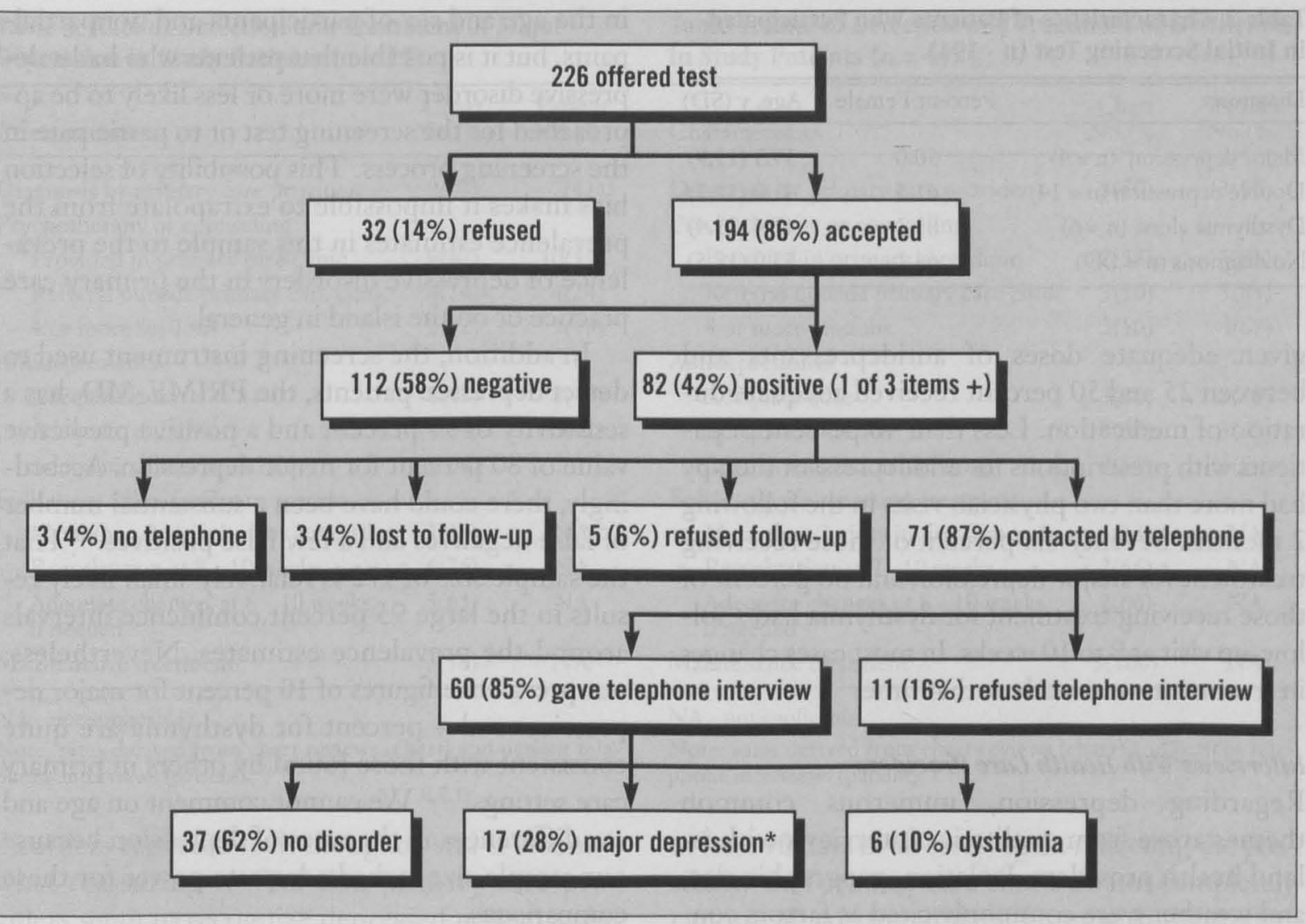

Figure 1. Sampling strategy.

*Of 17 patients with major depression, 14 also met criteria for dysthymia (double depression).

cent CI, 1 to 7 percent), and 86 percent $(n=149$, 95 percent CI, 81 to 91 percent) of our study sample had no depressive diagnosis. We found two cases in which the depression could have been a consequence of an underlying medical disorder (hypothyroidism and hypercalcemia). $\mathrm{Pa}-$ tients with major depression and dysthymia were more likely to be women and were somewhat younger than patients with no depressive disorders (Table 2).

\section{Recognition and Treatment Rates}

Tables 3 and 4 summarize the proportions of depressed patients whose disorder was detected by their primary care provider and who received adequate treatment according to the AHCPR treatment guidelines. ${ }^{19}$ These tables list detection and treatment rates derived from the chart reviews (chart) and from the patient telephone interviews (patient). In the chart reviews a depressive syndrome was broadly defined as any mention of depression, dysthymia, bereavement, adjustment disorder, or severe stress. Approximately 50 per- cent of the cases of major depression or dysthymia as determined by the PRIME-MD were detected by a primary care provider. Patients who had major depression diagnosed by their primary care provider averaged 7.1 of 9 depressive symptoms compared with those who did not have their condition diagnosed, who averaged 6.1 symptoms. Seven of 10 patients ( 70 percent) who had depression diagnosed by a primary care provider endorsed thoughts of death or suicide, but none of those 7 patients with unrecognized depression endorsed such thoughts.

Only 50 percent of the depressed patients were

Table 1. Prevalence of Mood Disorder Diagnoses in Study Population.

\begin{tabular}{lrrc}
\hline Diagnosis & Number & Percent & $95 \%$ CI \\
\hline Major depression & 17 & 10 & $5-15$ \\
Dysthymia & 6 & 4 & $1-7$ \\
No diagnosis & 149 & 86 & $81-91$ \\
Total & 172 & 100 & \\
\hline
\end{tabular}

$\mathrm{CI}$ - confidence interval. 
Table 2. Characteristics of Patients Who Participated in Initial Screening Test ( $\mathbf{n}$ - 194).

\begin{tabular}{lcc}
\hline Diagnosis & Percent Female & Age, $y(\mathrm{SD})$ \\
\hline Major depression $(\mathrm{n}=4)$ & 50.0 & $39.3(11.9)$ \\
Double depression $(\mathrm{n}=14)$ & 61.5 & $43.0(12.7)$ \\
Dysthymia alone $(\mathrm{n}=6)$ & 83.3 & $47.4(21.4)$ \\
No diagnosis $(\mathrm{n}=149)$ & 64.1 & $57.0(18.5)$ \\
\hline
\end{tabular}

given adequate doses of antidepressants and between 25 and 50 percent received adequate duration of medication. Less than 40 percent of patients with prescriptions for antidepressant therapy had more than two physician visits in the following 2 months. Seventy-six percent of those receiving treatment for major depression and 66 percent of those receiving treatment for dysthymia had a follow-up visit at 8 to 10 weeks. In most cases changes in treatment were made at that time.

\section{Interviews With Health Care Providers}

Regarding depression, numerous common themes arose from qualitative interviews with island health providers. Isolation, geographic size, and weather were commonly cited as factors contributing to depression on the island. It was also suggested that the island's remote and peaceful setting attracts persons attempting to escape from previous problems and environments to a more ideal existence. Many of the same difficulties follow these persons, however, and new difficulties related to life on the island can arise. Issues of confidentiality and stigma were commonly cited as barriers to detection and treatment of depression on the island. Of particular concern to residents is the possibility that others in the community will find out. Also, because of the small community size, patients might be forced to interact regularly with the health providers outside their practices. which makes discussion of personal and family problems difficult and potentially embarrassing.

\section{Discussion}

This study describes patterns of care for depression at the IIMC but cannot give accurate prevalence estimates for depression or dysthymia in the clinic. The 172 patients make up a convenience sample of patients who came to the primary care clinic during this 2 -month period. This sample might not be representative of the typical patient in the clinic. We found no significant differences in the age and sex of participants and nonparticipants, but it is possible that patients who had a depressive disorder were more or less likely to be approached for the screening test or to participate in the screening process. This possibility of selection bias makes it impossible to extrapolate from the prevalence estimates in this sample to the prevalence of depressive disorders in the primary care practice or on the island in general.

In addition, the screening instrument used to detect depressed patients, the PRIME-MD, has a sensitivity of 57 percent and a positive predictive value of 80 percent for major depression. Accordingly, there could have been a substantial number of false negatives and a few false positives. ${ }^{18}$ That the sample size of 172 is relatively small likely results in the large 95 percent confidence intervals around the prevalence estimates. Nevertheless, our prevalence figures of 10 percent for major depression and 4 percent for dysthymia are quite consistent with those found by others in primary care settings. ${ }^{1,7,8}$ We cannot comment on age and sex differences in the rates of depression because our sample size lacked adequate power for these comparisons.

The findings regarding the adequacy of care delivered in this setting are also limited by the small number of cases and that the chart reviews and patient interviews might have missed some treatments received. Because adequate data on the longitudinal treatment of depression were not obtained, we can only comment on the adequacy of acute-phase treatment for depression. Based on chart reviews and patient interviews, approximately 50 percent of patients had depressive disorders detected by their primary care providers. This rate is consistent with other research from urban and rural primary care clinics, $, 9,20-22$ which has found detection rates varying between 40 and 60 percent. The finding that patients with detected depressive disorders had more symptoms of depression than patients whose disorders were not detected is also consistent with other primary care studies, which point out a correlation between the severity of depression and functional disability and the likelihood of a depressive disorder being detected in primary care. ${ }^{23}$ An interesting finding along these lines is that 70 percent of patients with depressive disorders detected by their primary care provider endorsed thoughts of death or suicide. None of those with undetected depressive 
Table 3. Rate of Detection and Treatment of Major Depression in Study Patients $(\mathbf{n}=17)$.

\begin{tabular}{lcc}
\hline Characteristics & $\begin{array}{c}\text { Chart } \\
\text { No.(\%) }\end{array}$ & $\begin{array}{r}\text { Patient } \\
\text { No.(\%) }\end{array}$ \\
\hline $\begin{array}{l}\text { Diagnosis by primary care provider } \\
\text { Psychotherapy or counseling }\end{array}$ & $8(47)$ & $7(41)$ \\
$\quad \begin{array}{l}\text { Provided in primary care clinic } \\
\quad \text { Referral outside primary care clinic }\end{array}$ & $8(47)$ & $10(59)$ \\
$\quad 4$ or more sessions & $2(12)$ & $4(24)$ \\
Antidepressants & & \\
$\quad$ Adequate dose & $8(47)$ & $8(47)$ \\
$\quad$ Adequate duration & $4(24)$ & $8(47)$ \\
$\quad$ Adequate duration and dose & $4(24)$ & $8(47)$ \\
Follow-up after starting treatment & & \\
$\quad$ More than 2 visits in first 2 months & $3(38)$ & NA \\
$\quad$ Reevaluation at 8 - 10 weeks & $6(76)$ & NA \\
$\quad \begin{array}{l}\text { Adequate changes at } 8-10 \text { weeks, } \\
\text { if needed }\end{array}$ & $5(63)$ & NA \\
Maintenance treatment & $3(38)$ & NA \\
\hline
\end{tabular}

NA - not applicable.

Note: rates derived from chart reviews (chart) and patient telephone interviews (patient).

disorders reported such thoughts, and it is somewhat reassuring to find that primary care providers seem to recognize depressed patients who have such thoughts.

Approximately 50 percent of patients with depressive syndromes were offered office counseling by their primary care providers. The percentage reported by the patients is somewhat higher, and it is possible that the primary care charts did not completely capture what happened in the visits. Twenty-four percent of patients with major depression were referred for psychotherapy or counseling to another provider, usually a master's level psychotherapist. Only 3 of 17 patients with major depression, however, reported that they had more than four sessions of psychotherapy during the year preceding the interview. This proportion was somewhat higher in patients with dysthymia, although only 50 percent of those with chronic depression had four or more sessions of psychotherapy. Three patients consulted a psychiatrist off the island.

Of the patients with major depression or dysthymia, 50 percent were given prescriptions for an antidepressant medication, usually a selective serotonin reuptake inhibitor. According to chart reviews, only 50 percent of those prescriptions were for an adequate amount of time (90 days or more), but patients reported taking the antidepressants for
Table 4. Rate of Detection and Treatment of Dysthymia in Study Patients $(n=6)$.

\begin{tabular}{lcc}
\hline Characteristics & $\begin{array}{c}\text { Chart } \\
\text { No.(\%) }\end{array}$ & $\begin{array}{c}\text { Patient } \\
\text { No.(\%) }\end{array}$ \\
\hline $\begin{array}{l}\text { Diagnosis by primary care provider } \\
\text { Psychotherapy or counseling }\end{array}$ & $3(50)$ & $3(50)$ \\
$\quad \begin{array}{l}\text { Provided in primary care clinic } \\
\text { Referral outside primary care clinic }\end{array}$ & $2(33)$ & $5(83)$ \\
$\quad \begin{array}{l}\text { or more sessions } \\
\text { Antidepressants }\end{array}$ & $3(50)$ & $5(83)$ \\
$\quad \begin{array}{l}\text { Adequate dose } \\
\text { Adequate duration }\end{array}$ & $3(50)$ & $3(50)$ \\
$\quad \begin{array}{l}\text { Adequate duration and dose } \\
\text { Follow-up after starting treatment }\end{array}$ & $3(50)$ & $3(50)$ \\
$\quad \begin{array}{l}\text { More than } 2 \text { visits in first } 2 \text { months } \\
\text { Reevaluation at } 8 \text { - } 10 \text { weeks }\end{array}$ & $1(33)$ & $3(50)$ \\
$\quad \begin{array}{l}\text { Adequate changes at } 8 \text { - } 10 \text { weeks, } \\
\text { if needed }\end{array}$ & $2(66)$ & NA \\
Maintenance treatment & $3(100)$ & NA \\
\hline
\end{tabular}

NA - not applicable.

Note: rates derived from chart reviews (chart) and patient telephone interviews (patient).

at least 90 days in all cases, again reflecting the possibility that primary care charts do not completely capture all treatment data. Even with the higher estimates from the patient interviews, only about 50 percent of those with major depression or dysthymia were given an adequate trial of antidepressant therapy. This finding is quite consistent with those of others who have found that only about 50 percent of those started on an antidepressant medication in primary care receive adequate doses and duration of treatment. ${ }^{24}$

During the 2 months after starting antidepressant treatment, less than 40 percent of patients with major depression or dysthymia had two or more visits with their primary care provider. Seventy-six percent of patients with major depression and 66 percent of patients with dysthymia made a visit 8 to 10 weeks after starting treatment to reassess their response to initial antidepressant treatment. When patients had their response to initial treatment evaluated formally, appropriate changes in treatment were generally made at that visit. The low frequency of follow-up visits is a clear deviation from the AHCPR treatment guideline follow-up protocol, ${ }^{19}$ which recommends visits every 2 weeks during acute-phase pharmacotherapy, but it is quite consistent with findings of other primary care studies. ${ }^{21,24-27}$ This low frequency of visits for depression in primary 
care settings reported in both rural and urban locations could explain problems with adherence to antidepressant treatment. Recent studies that have increased the frequency of visits to primary care have shown improved adherence to antidepressant medication and improved outcomes compared with usual care. ${ }^{21,26}$

AHCPR guidelines recommend maintenance treatment for patients with three or more episodes of major depression and for patients with double depression. Of the patients with major depression, 38 percent received antidepressant treatment that appeared to be consistent with guideline-level maintenance treatment for recurrent major depression, although it is difficult to comment on the adequacy of this rate, because we do not have sufficient information regarding the lifetime course of their depressions (ie, if patients had a history of major depressive episodes). The rate of maintenance antidepressant treatment was 100 percent in those with dysthymia.

It should be mentioned that the AHCPR guidelines used to measure standard of care in this study were based predominantly on research conducted in mental health specialty settings and are not entirely evidence based. We used these guidelines as the best standard available to evaluate patterns of care at the IIMC.

Regarding the detection and treatment of depression in the rural island setting we studied, we estimate depressed patients and primary care providers face many of the barriers encountered in urban settings. There are unique barriers in rural settings, however. From our interview with island health care providers and our own experience working in the clinic, it is clear that issues of privacy are of particular concern, not only to island health care providers but also to patients. It is not uncommon for patients and providers to interact in social and civil roles outside the clinic. In such a small community, the fear of being labeled is considerable. The stigma of depression might influence detection and treatment of this and other mental illnesses in the clinic. Another barrier on the island is the lack of access to such specialty mental health treatment services as ongoing psychiatric care or partial or inpatient psychiatric hospitalizations. Three patients had to travel off the island to see a psychiatrist, which, because of the remote location of the island, usually means that the patient must take a day off work to travel back and forth. This geographic barrier could also limit the degree to which care provided in the primary care setting can be integrated with care provided by the consulting or treating psychiatrist.

\section{Conclusion}

Many problems seen in this island setting are similar to those seen in urban primary care settings. Although depression is a common and highly treatable disorder, only approximately 50 percent of depressed patients were so recognized by their primary care providers. Of those patients whose depression was diagnosed, only 50 percent received adequate acute-phase treatment, and few were seen every 2 weeks, as recommended in AHCPR guidelines. ${ }^{19}$ In recent years multifaceted interventions to improve the quality of care for depression have been developed and successfully used in primary care settings by research teams across the country. Katon and colleagues ${ }^{22}$ have summarized these approaches in a review of population-based disease management for depression in primary care. These interventions involve patient and provider education, an important role for those physician extenders as depression nurse specialists and mental health consultants integrated into the primary care practice, and proactive outcomes monitoring and follow-up. Because access to specialty mental health care in these remote settings is lacking, such intervention programs would have to be modified. A program on a rural island might include improved patient education and a physician extender, such as a depression nurse specialist, with back-up and consultation from a psychiatrist using telemedicine video equipment. San Juan Island, as well as other rural communities, would likely benefit from such multifaceted quality-improvement techniques.

\section{References}

1. Katon WJ, Schulberg H. Epidemiology of depression in primary care. Gen Hosp Psychiatry 1992;14: 237-47.

2. Wells KB, Stewart A, Hays RD, Burnam MA, Rogers W, Daniels $M$, et al. The functioning and well-being of depressed patients. Results from the Medical Outcomes Study. JAMA 1989;262:914-9.

3. Sullivan MD. Depression and disability from chronic medical illness. Eur J Public Health 1995;5:1-6.

4. Katon W. The impact of major depression on chronic medical illness. Gen Hosp Psychiatry 1996; 18:215-9. 
5. Greenberg PE, Stiglin LE, Finkelstein SN, Berndt ER. The economic burden of depression. J Clin Psychiatry 1993;54:405-18.

6. Perez-Stable EJ, Miranda J, Munoz RF, Ying YW. Depression in medical outpatients. Underrecognition and misdiagnosis. Arch Intern Med 1990;150: 1083-8.

7. Philbrick JT, Connelly JE, Wofford AB. The prevalence of mental disorders in rural office practice. J Gen Intern Med 1996;11:9-15.

8. Parikh SV, Wasylenki D, Goering P, Wong J. Mood disorders: rural/urban differences in prevalence, health care utilization, and disability in Ontario. J Affect Dis 1996;38:57-65.

9. Rost K, Wherry J, Williams C, Smith GR Jr. The process and outcomes of care for major depression in rural family practice settings. J Rural Health 1995;11:114-21.

10. Sussman JL, Crabtree BF, Essink G. Depression in rural family practice. Easy to recognize, difficult to diagnose. Arch Fam Med 1995;4:427-31.

11. Rost K. Practice variation in rural mental health care delivery systems. Gen Hosp Psychiatry 1996;18:1-2.

12. Rost K, Zhang M, Fortney J, Smith J, Coyne J, Smith RG Jr. Persistent poor outcomes of undetected major depression in primary care. In press.

13. Rost K, Humphrey J, Kelleher K. Physician management preferences and barriers to care for rural patients with depression. Arch Fam Med 1994;3:409-13.

14. Rost K, Smith GR, Taylor JL. Rural-urban differences in stigma and the use of care for depressive disorders. J Rural Health 1993;9:57-62.

15. Rost K, Smith GR, Matthews DB, Guise B. The deliberate misdiagnosis of major depression in primary care. Arch Fam Med 1994;3:333-7.

16. Goldman LS. Psychiatry in primary care: possible roles for organized medicine. Psychiatr Ann 1997; 27:425-9.

17. Taplin SE, Geyman JP, Gimlett D. The public hospital district for ambulatory care: an option to stabilize rural health services in crisis. J Am Board Fam Pract 1994;7:493-502.
18. Spitzer RL, Williams JB, Kroenke $\mathrm{K}$, Linzer $M$, de Gruy FV 3rd, Hahn SR, et al. Utility of a new procedure for diagnosing mental disorders in primary care: The PRIME-MD 1000 study. JAMA 1994;272: 1749-56.

19. Depression in primary care: detection, diagnosis, and treatment. Clinical practice guideline, quick reference guide for clinicians, no. 5. Agency for Health Care Policy and Research Depression Guidelines Panel. Rockville, Md: US Dept of Health and Human Services, Public Health Service, Agency for Health Care Policy and Research, 1993. [AHCPR publication no. 93-0550.]

20. Katon WJ. Will improving detection of depression in primary care lead to improved depressive outcomes? Gen Hosp Psychiatry 1995;17:1-2.

21. Katon W, Von Korff M, Lin E, Walker E, Simon GE, Bush T, et al. Collaborative management to achieve treatment guidelines. Impact on depression in primary care. JAMA 1995;273:1026-31.

22. Katon WJ, Von Korff $M$, Lin E, Unützer J, Simon GE, Walker EA, et al: Population-based care of depression: effective disease management strategies to decrease prevalence. Gen Hosp Psychiatry 1997;19: 169-78.

23. Simon GE. Can depression be managed appropriately in primary care? J Clin Psychiatry 1998;59 (Suppl 2):3-8.

24. Simon GE, Von Korff M, Wagner EH, Barlow W. Patterns of antidepressant use in community practice. Gen Hosp Psychiatry 1993;15:399-408.

25. Schulberg HC, Block M, Madonia MJ, Scott CP, Rogrigez E, Imber SD, et al: Treating major depression in primary care practice. 8-month clinical outcomes. Arch Gen Psychiatry 1996;53:924-32.

26. Katon W, Robinson P, Von Korff M, Lin E, Bush T, Ludman E, et al. A multifaceted intervention to improve treatment of depression in primary care. Arch Gen Psychiatry 1996;53:924-32.

27. Lin E, Katon W, Simon G, Von Korff M: Achieving guidelines for the treatment of depression in primary care: Is physician education enough? Med Care, 1997;35:831-42. 